\title{
Esas empeñadas luchas a que son muy aficionados los naturales de este país: un acercamiento a la etnicidad a través de la lucha canaria (1840-1943)
}

\author{
This earnest combat to which the natives of this country \\ are so prone: an approach to ethnicity through wrestling \\ in the Canary Islands (1840-1943)
}

\author{
Víctor Alonso \\ GRIES (Grup de Reçerca i Innovació Sport i Societat) \\ Universitat Ramon Llull \\ ucanca69@gmail.com
}

\section{RESUMEN}

El deporte, y especialmente los deportes tradicionales, son una contribución de primer orden a los procesos de construcción identitaria. Puede ser estudiado como realidad "en sí" (dotada de relativa autonomía, al modo de un campo social específico), o bien en modo de diacrítico social que permite caracterizar unas estructuras y procesos sociales que, a lo largo del tiempo, favorecen las transformaciones, sentidos y visiones legitimadas o denostadas contenidas en las prácticas. Este artículo trata la lucha canaria, un deporte tradicional que se manifiesta como constructo histórico revelador, al tratarse de un juego popular deportivizado que vive una intensa transformación a lo largo del siglo XIX y las primeras décadas del XX. Su estudio permite apreciar los distintos sentidos, apoyaturas y fundamentos sociales adscritos, mostrándonos un complejo espacio de relaciones donde sobresalen la figura del indígena (el guanche), la tradición histórica y una permanente conexión con la modernidad. Todo ello, suscrito al debate suscitado en el seno de la Antropología Social y las Ciencias Sociales a lo largo de las últimas décadas en torno a la etnicidad, la identidad y el deporte.

Palabras clave: Etnicidad; Identidad; Diacrítico social; Deporte tradicional; Lucha canaria; Ciencias sociales.

\section{SUMMARY}

Sports in general, and traditional sports in particular, make a key contribution to the processes linked to the configuration of any identity. These activities can be studied as a reality in its own right" (with a certain relative autonomy, as a part of a specific social subject), or as a diacritical social matter that enables us to characterize structures and social processes which, over time, could favour the changes, meanings and visions, whether considered legitimate or maligned, that are contained in these practices. This article deals with the traditional sport of lucha canaria [Canary-island wrestling], which has proved a revealing historical construct, to the extent that this popular game turned sports discipline underwent intense transformation during the 19th and early20th centuries. Its analysis provides an insight into the different social meanings, supports and principles associated with this activity, revealing a complex space of relations where the indigenous 
Guanche, historical tradition and an ongoing link with modernity are particularly relevant. All of this endorses the debate in recent decades in social anthropology and the social sciences regarding ethnicity, identity and sports.

Key words: Ethnicity; Identity; Social Diacritical Matter; Traditional Sports; Canary-Island Wrestling.

El estudio de la "lucha" canaria (en adelante, "lucha"), un "recurso auto identificador de los canarios y un diacrítico de su identidad" (Barreto, 1996:25), requiere ciertos marcos teóricos o conceptuales, tanto de cara a una mejor comprensión del fenómeno, como a evitar una deslavazada y (a nuestro juicio) erróneo tratamiento. Hasta ahora, la inmensa mayoría de trabajos realizados — desde la Academia o desde fuera de ella- tienen como punto en común con la antropología canaria (y, por extensión, la historiografía o la arqueología) el establecimiento y búsqueda de unos orígenes que son entendidos, de manera casi unánime, de raíz indígena. Partiendo de ahí, la práctica totalidad de las publicaciones han consolidado una visión de la "lucha" que enlaza directamente con el mundo indígena, partiendo de lecturas y relecturas acríticas de textos tomados como evidencia irrefutable. En ese sentido, respondiendo a la idea de transmisión directa y pura de valores propios del extinto y noble mundo indígena, la "lucha" se ha arrogado un privilegio comúnmente aceptado y legitimado en todos los ámbitos en que está presente: El de ser algo más que un deporte originario de indígenas que poseían "además de un cuerpo titánico un cerebro lleno de luz, [y que] no cabe duda que pertenecían a un grupo humano selecto" (La Prensa, 24 de junio de 1916: 1). Nuestra propuesta enlaza con estas cuestiones, encuadradas en el proceso de transformación vivido por la «lucha" a lo largo de un periodo histórico que arranca a mediados del siglo XIX y desemboca casi un siglo después, mediante la constitución de la Federación de Luchas Canarias, adscrita a la Federación Española de Luchas, en 1943.

Con objeto de incardinar el discurso y centrar el debate, partiremos de algunas cuestiones tales que la identidad, los diacríticos y la etnicidad, sin perder de vista lo arduo del propósito (Medina 2002: 27). Entenderemos la primera como un proceso de construcción grupal que se sustenta sobre diacríticos sociales ${ }^{1}$ que resultan interpretables en clave de consenso y conflicto, acogiendo "diversas estrategias de identidad basadas en la subdivisión interna del grupo, estableciendo toda una red —o una red de redes, si se prefiere- de relaciones establecidas a distintos niveles entre los diferentes miembros del grupo en cuestión" (Medina 2002: 28-29). Los diacríticos, como elementos de identificación, permitirán suponer la existencia de orígenes simbólicos comunes que trascienden del propio individuo, así como una orientación hacia el pasado al modo de la "historicidad". Y, siendo fundamentos de la "etnicidad" —esto es, en modo de una identidad construida y orientada al pasado (Medina 2002: 30-31) se presentan en un juego constante de interpretaciones y reinterpretaciones. El interés suscitado por la antropología social ante estas cuestiones se remonta a la década

\footnotetext{
${ }^{1}$ Esto es identificadores sociales y culturales definidores de la identidad, a través de los cuales se permite la elaboración de la singularidad cultural [siendo] instrumentos identificadores, desde donde es factible que el grupo pueda construir y después reivindicar su propia especificidad como tal". Y cuyo objeto es la "objetivación" de determinados "identificadores colectivos" que atienden a una realidad fragmentada y sin continuidad cultural.
} 
de 1960, pero la eclosión de los estudios sobre la etnicidad y sus aspectos vinculados en el seno de las ciencias sociales tomará forma en las décadas de 1980 y 1990 (Eriksen 1993: 1). Similar proceso vive el deporte, cuyo creciente interés como objeto antropológico se intensifica desde la década de 1980, en un proceso vivido, de manera parecida, por el resto de las Ciencias Sociales². Medina y Sánchez $(2003,2006)$ han abordado el particular desarrollo de la antropología del deporte en España desde la década de 1990, señalando tanto las corrientes seguidas, las obras de referencia, las obras y autores principales, o las temáticas tratadas.

En ese sentido, la "lucha" resulta ser un ejemplo del vínculo entre etnicidad y deporte: Se encuadra en un complejo espacio entendible al modo de un campo social, y su estudio escapa de las perspectivas sustancialistas (Bourdieu 1997: 14-15)3 que constituyen y legitiman toda una visión maniquea de "lo social". La pertinencia de "un profundo análisis del caso concreto" se antoja necesaria. Lo que permite romper con aquella visión del mundo social que determina una "relación ingenua entre el individuo y la sociedad", siendo sustituida "por la relación establecida entre dos modos de existencia de lo social, el habitus y el campo, la historia hecha cuerpo y la historia hecha cosa" (Bourdieu 2002: 41-2). De tal modo que no sólo sea necesario tratar su desarrollo temporal (la historicidad señalada por Lapierre) y los distintos aspectos partícipes de un proceso que supone la relectura moderna de prácticas físicas populares. Sino que también es preciso conocer los fundamentos sobre los que se asienta tal historicidad (emparentados de manera acrítica con la cultura indígena), o el desenvolvimiento posterior (que viene de la mano de un proceso de deportivización asimétrico, particular y establecido en torno a discontinuidades notorias).

Esto nos conduce a tratar tres puntos que consideramos relevantes. En primer lugar, la figura del indígena, que deviene actor central en la construcción histórica de la práctica. En consonancia con un debate abierto desde 1987 por Fernando Estévez y vigente hoy en día, casi treinta años después, tanto la preocupación por los orígenes, presente en la antropología insular desde el siglo XIX, como el modo en que es concebido el indígena (en sí, una categoría de análisis construida) orillando la década de 1940, en plena dictadura franquista y el momento en que se constituye la $\mathrm{Fe}$ deración de Luchas. En segundo lugar, trataremos algunos de los fundamentos sobre los que se asienta la "lucha" como práctica deportiva. Tanto la atribución y construcción de una filiación deportiva, como la integración dentro del proyecto moderno vehiculada en torno a los cuatro pilares o soportes de la Modernidad (Dubert y Martuccelli 2000: 27-39), permitirán entender la lectura hecha y su articulación a través del propio deporte, el regeneracionismo social o el regionalismo político. Por último, trataremos la influencia y presencia de la "lucha" en la diáspora isleña, especialmente dirigida hacia América.

\footnotetext{
${ }^{2}$ Ver, por ejemplo, Dunning 2003; Elías 1992; Thomas, Haumont y Levet 1988. En el caso de la sociología e historiografía del deporte en España, ver Barbero 1991; Moscoso 2006; Pujadas 2011.

${ }^{3} \mathrm{La}$ cual "Conduce a tratar las actividades o las preferencias propias de determinados individuos o determinados grupos de una sociedad determinada en un momento determinado como propiedades sustanciales, inscritas de una vez y para siempre en una especie de esencia biológica o -lo que tampoco mejora- cultural".
} 


\section{FUNDAMENTO Y BASAMENTO ÉTNICO: LA CONSTRUCCIÓN DEL INDÍGENA}

La atención suscitada por la figura del indígena canario y su devenir ha tomado en las últimas décadas un especial significado. Está presente en un intenso debate suscitado desde disciplinas como la antropología, la historiografía, la etnohistoria. E incluye lo que Estévez (1987: 67) señalaba como «una de las constantes más significativas de la historiografía canaria"; esto es, el uso sistemático de textos de los cronistas de la conquista y los primeros historiadores de los siglos XVI y XVII, en modo de "plagio o [...] aceptación acrítica de los mismos es algo que no por mucho repetirlo pierde su carácter de evidencia $"{ }^{4}$.

El redescubrimiento del archipiélago — desde el siglo XIV en adelante- y su conquista militar a lo largo del siglo $\mathrm{XV}^{5}$ propiciarán un contacto inicial entre europeos e indígenas. La "historización" del contacto con los indígenas canarios, tendrá como resultado una particular visión de éstos entre los siglos XIV y XVIII. Resultando tanto el "cómo son" de las primeras Historias, el "cómo eran" de las siguientes, o el "cómo éramos" dieciochesco. Así, el proceso de construcción de una identidad colectiva, partiendo de la figura del otro (Baucells 2009-10: 19) supondrá que la figura del indígena sea tratada, entendida y reconstruida de diferente modo, en concomitancia con el ideario tardomedieval, renacentista o ilustrado en que se gesta ${ }^{6}$.

Las descripciones etnohistóricas sobre los indígenas, su vida, usos y costumbres quedarán condicionadas por el pensamiento occidental y, en menor medida, por la observación directa (Farrujía 2010: 64). Durante los siglos XV y XVI, confluirán en torno al resquebrajamiento del mito del salvaje medieval (Bartra 1996: 24ss.; Baucells 2012: 72-99; Estévez 1987: 63-70). Partiendo de una visión condicionada por el pensamiento judeo-cristiano y la tradición clásica, el "otro" —el indígena canario- será entendido desde una ideologización cambiante, cuya posterior vinculación con la "dialéctica americana" es evidente (Baucells 2012: 100-198; Farrujía 2010:66). La relación entre naturaleza (humana) y cultura será vehiculada mediante la crítica a la civilización occidental (Bartra 1996: 272), la representación y recreación del ideario lascasiano y los modelos derivados en torno a una "alteridad próxima" (Baucells 2012: 149- 156).

\footnotetext{
${ }^{4}$ Especialmente Baucells y Farrujía han tratado esta cuestión a lo largo de la última década, suscitando un intenso debate que se enmarca en un contexto científico más amplio que se manifiesta en la producción científica de antropólogos (Baucells 2012: 50-58) o historiadores de la arqueología (Farrujía 2010: 35- 61).

5 Producida entre 1402 y 1496, aglutina dos modelos claramente definidos. Hasta 1477 es de carácter señorial, emprendida por franco-normandos y con el apoyo de Castilla. La empresa expansionista de los Reyes Católicos toma forma en la conquista de Gran Canaria (1483), La Palma (1493) y Tenerife (1496). Esto supone que, tras 1496, convivan dos fórmulas, el señorío y el realengo, vigentes hasta el siglo XIX.

${ }^{6}$ Baucells (2009-2010:24-26; 2012:72-244); Estévez (1987:63-131) y Farrujía (2010:61-82) inciden especialmente en la trascendencia de la figura del indígena ante la construcción de una identidad definida, algo que supone, incluso, la existencia de cierta "disputa semántica" en la concepción del aborigen o indígena, que queda enmarcada en la obsesión por los orígenes presente en los estudios antropológicos en Canarias desde el último tercio del siglo XIX, y se extiende hasta la actualidad (Estévez 1987: 163-166). A nuestro juicio, Farrujía recoge el testigo de manera brillante, en su análisis conceptual y la relación establecida con la arqueología y la historia (2010:69:82).
} 
En consecuencia, el indígena —el guanche-, será concebido de modo virtuoso, libre y feliz en su encuentro con el mundo natural y su naturaleza propia, más allá de una bestia salvaje. Se trata, en este caso, de un doble proceso de asimilación y proyección, donde las sociedades nobles y cortesanas europeas construyen un imaginario civilizado del salvaje, donde toma especial relevancia el baile, los banquetes, la caza, la lucha, o la fiesta, en concomitancia con prácticas de ocio netamente cortesanas (Vigarello 2005). Por ejemplo, será habitual la celebración de fiestas donde se aluda al mundo salvaje, incluyendo la celebración de torneos, bailes corales, juegos o simulacros de combates de manera frecuente. En ocasiones, la presencia de indígenas o bestias salvajes atenderá a la curiosidad y despliegue de lo exótico ${ }^{7}$, testimoniando el alcance del poder sobre que se sustentan estos balbuceantes imperios.

De tal modo que, entre los siglos XV y principios del XVIII, la representación del indígena canario responderá a un ideario corporal y moral donde se destacan sus virtudes (Baucells 2009-2010: 12-24; 2012: 72-244) ${ }^{8}$. Sus formas corporales proporcionadas, le permiten hacer "alarde de sus gracias en saltar, correr, bailar [...] con mucha ligereza y mudanzas, luchar y las demás cosas que alcanzaban [a] hombres tan valientes, de tanta fuerza y ligereza, y de tan delicados ingenios" (De Espinosa 1980: 176). Descripciones que vendrán de la mano de la desaparición de los indígenas canarios y su cultura, a fines del siglo XVII, lo que acarreará una visión del indígena desde un enfoque más arqueológico que etnográfico (Farrujía 2010: 64).

El pensamiento ilustrado supondrá el comienzo de «una seria especulación antropológica" (Stocking, en Estévez 1987:11) alrededor de la figura del indígena canario. Fundamentada sobre la vigencia de un "buen guanche", muestra diferencias para con el "buen salvaje" roussoniano, al permitir reivindicar cierta naturaleza perdida y, a través de sus bondades y virtudes, mostrar cierta visión negativa de la sociedad dieciochesca. Es una figura que permitirá el encuentro con enseñanzas morales e históricas sobre la recreada base de una cultura desaparecida "lamentablemente" (Estévez 1987: 17). En ese sentido, la obra de José Viera y Clavijo resulta clave, especialmente en su propósito de afianzar una consideración pancanaria del indígena mediante la generalización de «una idea del origen, carácter, usos y costumbres de sus antiguos habitantes". Para Viera, "nuestros antiguos isleños, por genio, o por educación, eran extremadamente inclinados a los juegos, y regocijos públicos". Ello le permite establecer paralelismos entre los juegos indígenas y los juegos olímpicos de la Grecia clásica, algo que permitirá dignificar el pasado indígena9. Todo ello en un contexto don-

${ }^{7}$ Tal y como novela José Saramago en El viaje del elefante (2008): El periplo por media Europa de un elefante asiático guiado por su cornaca, como regalo de boda del Rey Juan III de Portugal al archiduque Maximiliano de Austria.

${ }^{8}$ Y que vendrán acompañadas de una descripción de los juegos físicos y bailes sometida, de manera acrítica (o intencionada), a una relectura y reinterpretación interminable.

${ }^{9}$ Viera relata la existencia de convites de carácter nacional entre los indígenas, lo que permite la instauración de periodos de paz, auspiciados por el generoso dispendio de monarcas. En estos periodos se celebran una serie de juegos que "tenían mucho de Heroycos, pues consistían en Músicas, Bayles, Luchas, saltos, Carreras, Tirar piedras, Levantar pesos, Trepar y executar otras acciones de ligereza y de valor" (De Viera 1992: I, 159-165). Esta idea seguirá estando presente en los textos de escritores e defensores de las virtudes de la "lucha", ya en el primer tercio del siglo XX. 
de la búsqueda de antecedentes y genealogías se ha establecido entre las élites dieciochescas locales (Baucells 2012: 198-244) ${ }^{10}$, lo que comporta una concepción indigenista de la identidad (Baucells 2012; Estévez 1987).

En una hábil puesta en valor de la figura del indígena por el pensamiento romántico insular (Estévez 1987: 83-88), se gestará cierta "tradición interna" (op. cit.: 85-86). Establecida en torno a distintas variables, el indígena será exaltado al albur del intimismo, siguiendo un credo estético, espiritual y moral que ensalza su figura de vencido $^{11}$. Tal sentido y propósito de dignificación tendrá continuidad en la denominada "escuela regionalista" (op. cit.: 88). Y deja su huella en el pensamiento positivista decimonónico, del que la balbuceante antropología isleña es deudora, y cuyo propósito pasará por reivindicar la cultura y valores morales del indígena, pretendiendo conferir a las islas el carácter de "estado histórico" (Cuscoy, en op. cit.: 98).

En consecuencia, a lo largo del siglo XIX, confluirán los postulados románticos y las perspectivas positivistas alrededor de la figura del indígena. Disciplinas científicas como la arqueología (Farrujía 2010: 83ss.) o la antropología (Estévez 1987: 89ss.) convergerán en perspectivas evolucionistas (Estévez 1987: 133- 166; Farrujía 2010:116-118), o raciológicas (Estévez 1987: 107-132), teniendo como resultado un "tormento intelectual" (op. cit:: 102) de difícil resolución para la antropología insular decimonónica ${ }^{12}, \mathrm{y}$ que queda encuadrada en las tesis de la evolución, civilización, raza y progreso (op. cit.: 150). En esta tesitura, a principios del siglo XX, Bethencourt Alfonso fabulará la existencia de unos "Juegos Beñesmares", o "grandes fiestas nacionales" donde "entregábanse los reinos con delirante entusiasmo a variados deportes varoniles, banquetes, bailes y otros espectáculos ${ }^{13}$. El dilema proseguirá durante las primeras décadas del

${ }^{10}$ Bajo la denominación de "síntesis", Baucells ubica su origen a lo largo del siglo XVII, en un propósito de búsqueda de legitimación social mediante la filiación con menceyes, guanartemes (esto es, tal y como se denomina a los dirigentes o reyes indígenas de las islas de Tenerife y Gran Canaria) o conquistadores.

${ }^{11}$ Un ejemplo palmario se encuentra en la figura de Sabin Berthelot, naturalista, historiador, etnólogo y agente consular francés. Quien, desde la premisa de la preservación de los caracteres principales de la raza "guanche", recreará "un retrato psicológico, filosófico y moral de los aborígenes extrapolando la visión que se había formado de los campesinos canarios de su época" (op. cit.: 18).

12 Tal que "buscar una espita que permitiera situar a los aborígenes en las corrientes progresivas de la historia" (Estévez 1987: 100), ante la tesitura eurocéntrica del evolucionismo, y con el fin de "elevar el estatus histórico de la cultura aborigen que justifique la dignidad de su historia y su papel dentro del proceso evolutivo de las "grandes culturas" (op. cit.: 102). La recurrida "distorsión de los esquemas de la evolución cultural" se justificará en la adscripción a la estrategia raciológica, así como "la necesidad de valorar lo aborigen para integrarlo como elemento diacrítico de la identidad histórica canaria" (ibid.).

Así, mientras se equiparan los cráneos guanches con el recién descubierto Cro- Magnon, se enlazará el pasado indígena y su raigambre con el mundo clásico, al sostenerse que los indígenas canarios son "los atlantes refugiados al pie de las montañas" (Bethencourt, ibid.).

13 Bethencourt Afonso, (1994: 311). El planteamiento guarda paralelismos con el mundo clásico. Pero, a diferencia de sus antecesores (como Antonio de Viana o José Viera y Clavijo), Bethencourt Afonso se forma en Paris como médico, compartiendo con otros médicos y científicos canarios la filiación y estrecha relación con Francia. Como poco, habrá de conocer la obra y labor de Pierre de Coubertain, siendo coetáneo a la creación del olimpismo moderno. Ello permite aseverar la pretensión de recrear unos "Juegos Olímpicos Guanches", como elemento distintorio, que glorifica el pasado indígena y ennoblece el constructo histórico perseguido. 
siglo XX, hasta los primeros años del régimen franquista, donde queda descartado "cualquier planteamiento regional no españolista", tal y como ocurre en el caso de la arqueología en Canarias (Farrujía 2010: 195).

\section{LA "LUCHA" COMO DIACRITICO SOCIAL: FUNDAMENTOS Y SOPORTES}

La cambiante configuración del indígena se acompañará desde fines del siglo XVIII y a lo largo del XIX, de un intenso proceso de transformación social, entendible en clave de modernidad occidental. Los cambios conducentes a esta nueva idea de sociedad $^{14}$ serán interpretados mediante concepciones dicotómicas y antagónicas de lo social (lo moderno frente a lo pre-moderno); el empleo de metáforas organicistas como recurso explicativo (y legitimador) de la nueva realidad; y la ineludible visión de un progreso lineal, imparable y unidireccional.

Tal y como hemos referido, tanto la identidad (entendida como construcción inacabada), la etnicidad (con su carácter de historicidad) y los diacríticos (al modo de marcadores fijados de manera selectiva) apuntan a procesos que, lejos de tener un carácter "natural", muestran construcciones dotadas de sentido y sujetas a los contextos en que se desenvuelven. En su desarrollo histórico - tanto en un sentido científico, como en base a su historicidad-, la "lucha" y otros juegos o prácticas físicas tradicionales canarios (como el "juego del palo", el "salto del pastor" o la "vela latina") permiten ver qué actores toman parte de su construcción, el modo en que lo hacen y, sobre todo, la legitimación alcanzada. Al respecto, tratamos algunas claves a nuestro juicio relevantes y que forman parte del proyecto moderno (Alonso Delgado 2015).

\section{EL SENTIDO DEPORTIVO}

El deporte forma parte del proceso de modernización (con sus contradicciones y conflictos derivados). Es un diacrítico social de primer orden (Calvo, en Medina y Sánchez 2003; Medina 2002), al que las ciencias sociales han realizado un acercamiento, cuando menos, controvertido: El estudio del deporte por parte de las ciencias sociales ha sido situado en desventaja ante tradiciones científicas "más serias y graves" (dada su indefinición y el poco peso específico de las disciplina de estudio); ante la irreverente crónica deportiva, ha adquirido un estatus que va entre el permanente aguafiestas y el gurú admonitorio; y ante todas aquellas disciplinas bio-médicas constituidas alrededor de la performance, tildado de escasamente útil y de aportar más problemas que resultados ${ }^{15}$.

Coincidiendo con Vigarello y Holt (2005), el siglo XIX se antoja central para comprender el modo en que diferentes juegos físicos populares convergen con el proceso

${ }^{14} \mathrm{O}$ sea, el origen moderno; el soporte explicativo y legitimador sobre la metáfora del sistema; la regulación de tiempos y espacios sociales alrededor del mundo del trabajo; y la homología y apoyatura sobre el Estado-Nación como muestra de una sociedad particular y definida, así como marco de la misma.

15 De modo que, tal y como ha señalado MacClancy (1996:1), "sports are intrinsically innocent and liberating; enjojable to pursue but not profitable to study". 
de deportivización (Elías y Dunning 1992) ${ }^{16}$ y adquieren un nuevo sentido. Esto comporta diversas situaciones. En ocasiones, se "civilizarán" prácticas, refinándose hábitos y gustos cortesanos, así como el control y regulación de la violencia (así Elías estudia la caza del zorro en la Inglaterra del XVIII y XIX). Al amparo de un proceso de difusión cultural se producirá una nueva legitimación y reglamentación de la violencia, cuya gratuidad queda fuera de lugar. Y, al igual que sucede con el novedoso "estilo deportivo", su civilidad será signo de distinción social (Bourdieu 1996, 2000). En otras ocasiones, se producirá una relectura de prácticas y juegos físicos ya existentes (como pasa con el fútbol en las schools inglesas, la savate francesa, o el lacrosse canadiense). En este caso, no sólo habrá una inclusión de nuevas reglas o normas. Sino que también se delimita qué o no es deportivo, así como la capacidad de definición por parte de los actores sociales implicados. Otras veces, se producirá un rescate o revival de prácticas o propósitos extintos, como sucede con las pruebas de sortija a caballo o, como ejemplo más socorrido, los modernos Juegos Olímpicos. Con todo, no tiene cabida la tentación de atribuir un carácter "predeportivo" ${ }^{17}$ a estas prácticas, que habrán de entenderse como prácticas significadas en contextos específicos, y cuyas atribuciones serán dotadas de un sentido propio y particular.

Los deportes tradicionales encuentran acomodo en este contexto, permitiendo ver, a modo de diacrítico social, su vinculación con la etnicidad (como proceso de construcción colectiva, común, "desde adentro", y dotado de historicidad). Su surgimiento deviene paradójico. Pues, sobre la apoyatura del moderno deporte, enlazan tanto con el desencantamiento y crítica a la modernidad, como con el despegue de disciplinas científicas que pretenden entender, etiquetar y establecer relaciones con/entre "nosotros" y el "Otro", tales que la geografía, la antropología física, la arqueología, la etnografía, la etnología, la sociología, etc. Dando lugar a una realidad poliforme, en la que el estudio de los juegos y deportes tradicionales requiere una consideración de lo "particular concreto" (Marx 1976) de cara a constatar las lógicas y sentidos particulares, los procesos históricos, las convergencias con otras prácticas deportivas (tradicionales o no), o los dispositivos institucionales donde son enmarcadas o excluidas las diferentes prácticas. La "lucha" ilustra cómo la recreación y aceptación de un pasado y orígenes comunes facilitan la articulación de "el proceso de identidad y etnicidad de las islas está relacionado con el mantenimiento y desarrollo de esta comunidad de símbolos". Permitiendo no sólo la construcción de marcadores simbólicos ante el "otro" y entre "nosotros" —entre islas - (Barreto 1996: 24). Sino que, asimismo, acogiendo un proceso identitario entendible en el contexto particular y propio de los deportes y la "lucha", tal y como hemos tratado en otros trabajos (Alonso Delgado 2014, 2015).

${ }^{16}$ (Elías 1992:34. También en 48; 161ss.; 185ss.). Se contempla un progresivo ordenamiento de las prácticas físicas, el establecimiento de códigos reguladores y, lo que es más importante, la asunción por los actores implicados de tales códigos, su constitución y trascendencia. Así, se pretenderá una reglamentación de las emociones y la conducta social amplia y abarcativa.

17 "Los antiguos juegos físicos no son deporte: No cuentan ni con el dispositivo institucional, ni con la organización selectiva. Pero están muy presentes [en] la Europa de los siglos XVI, XVII y XVIII, de manera muy intensa incluso, cotidianos, desmenuzados, contemplados, instalados en la mayoría de los espacios y de los instantes de la vida; también existen debido a los efectos sociales o físicos que se espera de ellos: los movimientos, la puesta en escena, los rituales muy pensados" (Vigarello y Holt 2005: 229). 
De este modo, la explicación del origen y posterior devenir histórico en modo de "plagio o [...] aceptación acrítica" (Estévez 1987: 67), se ha sustentado en diferentes relecturas de obras especialmente redactadas entre los siglos XVI y XIX. La búsqueda y establecimiento de orígenes dirige las miras hacia el indígena casi de manera unánime $^{18}$, para establecer una cronología y un desarrollo evolutivo posterior que confluye, de modo inevitable, en la constitución de una Federación de Luchas, en $1943^{19}$. De este modo, se pretende una doble legitimación, dado el origen indígena (testimoniando la presencia de valores ancestrales que han pervivido al paso del tiempo ${ }^{20} \mathrm{y}$ su conformación como práctica deportiva moderna y civilizada.

Como juego físico reinterpretado, la "lucha" toma un sentido novedoso a mediados del siglo XIX. En Tenerife se celebran combates de relativa importancia en torno a la década de 1840 en el contexto de la fiesta cívica. Como espectáculo dispuesto en torno a normas, celebrado en espacios acotados, con contratación de luchadores, y reparto de premios en metálico, toma forma ya en la década de $1850^{21}$. Se trata de una oferta de ocio urbana de carácter más o menos estable, cuyo desarrollo e implantación depende de la importancia de pueblos, villas o ciudades ${ }^{22}$. La celebración de estos espectáculos públicos y urbanos se producirá al albur de la beneficiosa "atracción de forasteros". Hacia 1853 se hace referencia a aforos que superan los 1.500 espectadores $^{23}$ en una ciudad, Santa Cruz de Tenerife, cuya población apenas alcanza los 10.000

\footnotetext{
${ }^{18}$ No siempre se ha tenido esta consideración. Entre las décadas de 1940 y 1960 se cuestiona su origen netamente indígena (por ejemplo, ver Ayala 1977; Pérez 1984: 8), en consonancia con "cualquier planteamiento regional no españolista", tal y como apunta Farrujía (2010: 195) al hablar de arqueología. Ayala (1977: 60) señala la posible importación de la práctica desde Suiza tras la conquista de las islas de Realengo, en 1496. Recientemente, García y Casanova (2014) apuntan un origen morisco al estudiar representaciones pictóricas de la expulsión de los moriscos de España.

${ }^{19}$ Las tesis evolutivas de la "lucha" pasan por considerar tres etapas (Antequera 1996: v31ss.; Hernández et al. 2000: 28) pretendidamente históricas y basadas en un tratamiento acrítico y deslavazado de fuentes y datos. Como ejercicio inacabado de búsqueda de orígenes, concurre en un debate presente en las ciencias sociales del deporte, tal y como refleja Alfred Wahl (1996, 2002) en su estudio del fútbol.

El establecimiento de esta cronología toma forma en base a los escritos de Emilio Rivero (2007), en su intento por legitimar y atribuir un sentido moderno una práctica popular en pleno proceso de deportivización.

${ }^{20}$ "Como recurso autoidentificador de los canarios y un diacrítico de su identidad", la "lucha" pasará por ser dotada "de significados que simbólicamente representan el carácter y la idiosincrasia de la cultura aborigen: nobleza, sencillez, destreza, agilidad, admiración al vencedor y respeto al vencido" (Barreto 1996: 25).

${ }^{21} \mathrm{Tal}$ y como sucede en otros contextos, europeos o americanos, con la capoerira, la savate, el boxeo, el wrestling, o la lucha bretona.

${ }^{22}$ En general, serán las poblaciones de mayor tamaño las que establezcan una oferta cuya intensidad irá en función de diversas variables, nacidas de la interrelación entre los capitales específicos (un público o practicantes expertos) y la capacidad de atracción de las poblaciones.

${ }^{23}$ Construida con motivo de la Feria de Diciembre de 1853 en la Alameda de Branciforte. Se trata de «un local adecuado y cómodo y con gradería por el estilo de las Plazas de toros de la Península" (Eco del Comercio, 26 de noviembre de 1853: 3), bautizada con el patriótico nombre de "campo de Daoiz y Velarde" (ibid., 10 de diciembre de 1853: 3-4). En Santa Cruz de Tenerife, hasta bien entrada la década de 1870, las luchas multitudinarias se celebrarán en los patios del antiguo convento franciscano. En San Cristóbal de La Laguna, en los patios de la antigua Alhóndiga, donde se construye un "luchadero".
} 
habitantes. Se trata, en gran medida, de una movilización de públicos numerosos que recorren 10 o 20 kilómetros para presenciar espectáculos dominicales (De Olivera 1969: 282). Ya a fines de 1890 en Las Palmas de Gran Canaria y Santa Cruz de Tenerife se sabe de locales o espacios habilitados cuyos aforos son de 4.000, 5.000 u 8.000 espectadores: La apertura hacia públicos urbanos supondrá un mayor tratamiento como espectáculo de masas, socialmente transversal (o, al menos, así se pretende), y de fuerte impronta mercantil, en un proceso paralelo y común con las peleas de gallos ${ }^{24}$. Asimismo, los intentos por regular la práctica nos retrotraen a los inicios de la década de 1850. Los primeros reglamentos localizados datan de 1853 y 1854 (Alonso Delgado 2014, 2015). De alcance limitado a los encuentros que regulan, al igual que ocurre con el posteriormente localizado en Cuba, en 1873 (Antequera 1996: 107-108), comparten un interés común en torno a las formas y tiempos, la regulación de los combates y la dotación de premios.

Entre 1880 y 1910 se intensificará la progresiva deportivización de la práctica. Junto a la regularización de espacios de práctica y consumo, se incorporan visiones concurrentes en torno al rendimiento deportivo (la antropometría, el entrenamiento técnico-deportivo o la condición física de los atletas). Se trata de un periodo donde los discursos y los términos deportivos alrededor de la "lucha" hacen su aparición, ganando las crónicas periodísticas en precisión y detalle. La prensa decimonónica testimoniará el "giro lingüístico" (Cabrera 2002) que experimenta un "guanchinesco espectáculo" que pasa a ser tratado como "sport canario" durante los primeros años de la década de 1900, en correlación con la expansión de prácticas y consumos deportivos. De otra parte, la dotación de locales de ensayo con pesas, barras y artilugios gimnásticos, se producirá casi a la par que la constitución de sociedades o partidos de luchadores, en torno a la década de 1900 (Alonso Delgado 2014, 2015)25.

La celebración de espectáculos en espacios abiertos "Como en la Península en una plaza; pero llana sin asientos ni preparativos, en campo raso y al aire libre" (La Aurora, 19 de septiembre de 1847: 20), seguirá siendo frecuente. Pero hacia 1914, los signos de deportivización son más que evidentes. Consolidada como un espectáculo deportivo, de fuerte impronta mercantil y legitimado como exponente de la "raza guanche", por más que se pretenda recrear el uso espontáneo de eras y huertas, los combates de cierta entidad y atención mediática se celebran en espacios cerrados y de acceso restringido al pago de entradas. En Santa Cruz de Tenerife, capital provincial, desde principios de 1880 se usa el Circo Duggi, un recinto de madera y lona con un aforo que ronda los 1000 espectadores. A principios de 1900, momento en que ha sido demolido el Circo Duggi, se celebrarán luchas en la Plaza de Toros (con aforo de 5.000 espectadores), la gallera de la calle Santa Rosalía, o el velódromo de carreras (que hacia 1901 no registra actividad deportiva). Hacia 1915 ya se suman dos locales de variedades (cuyos aforos

\footnotetext{
${ }^{24}$ Con quien comparte tanto un espacio de práctica, consumo y sociabilidad netamente masculino, como el papel y presencia de promotores, terminología, espacios y tiempos comunes.

${ }^{25}$ La constitución de sociedades luchísticas se sucederá especialmente a lo largo de la segunda mitad de la década de 1910, siendo localizadas al menos 31 sociedades que incorporan su práctica en las islas occidentales entre 1913 y 1936, lo que también responde al alto grado de popularización del espectáculo y su práctica. En este caso, la lucha canaria copará un espacio que en el resto del Estado español será hegemonía del fútbol, el ciclismo, el pedestrismo o la pelota, en todas sus variantes.
} 
oscilan entre los 600 y los 1.400 espectadores), los campos de deportes instalados en la ciudad, o los locales habilitados por las sociedades luchísticas. Desde mediados de 1920 se incorporarán las salas de cine al aire libre, que también acogerán combates boxísticos. Se trata, por tanto, de un proceso temporal y espacialmente asimétrico donde los espacios públicos, abiertos, como las plazas o huerta van cediendo protagonismo a los espacios acotados ${ }^{26}$, pese a los intentos de Emilio Rivero por "hacer desaparecer el vergonzoso grado de mercantilismo a que ha llegado nuestro deporte en estos últimos tiempos" (La Prensa, 6 de septiembre de 1929: 2), celebrando "luchas" con bregadores nóveles en plazas públicas con entrada pública y gratuita ${ }^{27}$.

Los propósitos por dotar de reglamentos de carácter universal toman forma a partir de la década de 1910, especialmente de la mano de Emilio Rivero Rodríguez, quien promueve la creación de campeonatos de carácter insular y regional, así como un Reglamento de Luchas con fallido alcance regional, en $1925^{28}$. Bajo el paraguas del "nuevo estado" franquista, una vez constituida la Federación de Luchas Canarias (1943), se retomará desde 1945 la idea y propósito universal. Si bien hasta 1957 no se redacta un fallido Reglamento Técnico, es en 1960 cuando se redacta un Reglamento Técnico Unificado (Ayala 1977: 15-25).

\section{EL PROYECTO MODERNO: REPRESENTACIÓN, REGENERACIÓN Y DISCIPLINAMIENTO}

En todo el proceso, la impronta burguesa es notoria, estableciendo representaciones de lo regional o folklórico desde fines de 1880 en distintos espacios y formas de sociabilidad propios. La organización de bailes típicos, "luchas" o festivales regionales comenzará a ser frecuente a partir de la década de 1900, especialmente conjugando utilidad, divertimento y presencia social: Se trata de un tipismo amigable y benévolo, donde la asistencia y participación de las clases populares queda circunscrita al pago de entradas o a la participación directa en forma de bailadores, cantadores, luchadores, jugadores de palo o bueyeros. De manera ecléctica, los programas intercalan números puestos al servicio del sano divertimento ${ }^{29}$.

${ }^{26}$ El control del orden público, el cobro de entradas y pago de impuestos de timbre, así como el sentido de la privacidad amparado por los recintos cerrados, conculcan la imagen y sentido del espectador, que adquiere y hace valer sus derechos mediante el pago de entrada.

${ }^{27}$ Bajo el paraguas de la sociedad Unión y Progreso de Tegueste, localidad autodenominada como "cuna de la lucha canaria", y "patria chica" de Rivero.

${ }^{28}$ El documento, publicado en un opúsculo editado por el periódico de mayor tirada en el archipiélago (La Prensa), se redacta, con toda probabilidad, al amparo del Grupo Gimnástico Laguna (1924), una sociedad que pretende "fomentar la cultura física" mediante un programa que acoge "las luchas, el boxeo, levantamiento de pesos, lanzamiento de discos, saltos de trampolín". En 1925 se constituye la Federación Regional de Fútbol. También la Federación de Pelota Vasca.

${ }^{29}$ Al comparar la evolución de los programas elaborados, se aprecia cómo la participación popular irá abriéndose en este doble sentido: la presencia de programas eclécticos, donde aparecen "luchas", combates de esgrima o el canto de arias operísticas se produce desde el principio de estos espectáculos, pensados por y para el divertimento de un gusto burgués. A lo largo del Directorio y la Dictadura primorriverista se incidirá en la presencia, casi exclusiva, del elemento popular, en eventos entendidos en clave de "obra patriótica" donde se pretende la "afirmación de los valores regionales, en aquello que tienen de típico, de original y carac- 
A medida que transcurre el siglo XX, el carácter popular atribuido a la "lucha" (como práctica y espectáculo) acompañará su dimensionamiento como diacrítico identitario. Su sentido deportivo acogerá una compleja consideración de "lo popular". Donde conviven cierto rechazo (considerando la proclive orientación al desorden por las clases populares, así como el cobro de emolumentos elevados, en contra del ideal amateur), con el encumbramiento racial (que confluye en la figura del guanche-sportman) y de la mano de unas virtudes y ventajas higiénicas (en un sentido regeneracionista) notorias. Estos tres aspectos permiten reforzar determinados aspectos del diacrítico, hacerlos atemporales y actuales a la vez. Pues, siendo una práctica reinterpretada, su carácter popular vendrá apuntalado desde una perspectiva elitista (Grignon y Passeron 1992). La representación ideológica resultante pasará por defender y justificar la existencia de un buen espectáculo tutelado principalmente por promotores y empresarios, donde la defensa del orden (en un sentido amplio) y la emoción encauzada ${ }^{30}$ se aparecen de la mano de un argumentario moral (el honor, la tradición, la hombría...) adscrito a un universo masculino que prohíbe, restringe o limita la asistencia de público femenino y niños aun en la década de $1920^{31}$. Como resultado, esta compleja y poliforme muestra de "identidad regional" será puesta en juego ante los sorprendidos ojos de los invalids extranjeros que residen en el Gran Hotel Taoro (Diario de Tenerife, 6 de diciembre de 1888: 2), antecediendo la puesta en marcha de cierta "propaganda de la isla" en modo de espectáculos ofrecidos a touristas, ya en la década de $1930^{32}$. Formará parte en la recepción de autoridades, ministros, monarcas o prelados, donde la exhibición de luchadores se escenifica en espacios habilitados de manera intencionada, al modo de eras o "una plazoleta cubierta de césped, salpicada de palmas y dragos canarios" (Sánchez 1987: 57). La presencia de damas y personajes ilustres hará que los luchadores vistan decorosamente trajes de punto, como parte de un espectáculo culto, al servicio de personas de buen gusto.

También alcanza el ámbito militar. La presencia cuartelaría se produce desde, al menos, la década de 1900, en las fiestas de las armas, aunque desde 1861 se constata la presencia de al menos 80 "militares y paisanos" en una "lucha magna" celebradas en

terístico" (La Prensa, 1 de mayo de 1924: 1). En el periodo republicano se manifestará no sólo la apertura a grandes públicos (al integrar, en un mismo evento, "exhibiciones de base-ball [la] Danza del Arco, de Tegueste, [o] números de excentricidad por Mr. Whisky, Chicote, y el popular Guajiro" (Ibid., 29 de Junio, 1935, p. 6), sino que se reforzará la idea de lo popular a través del divertimento, la participación directa, y la consolidación de un sentido propio.

${ }^{30}$ En 1908 se pide a la policía municipal desde las páginas de El Pueblo que intervenga en las discusiones del público, impidiendo éstas para beneficio del desarrollo del espectáculo y evitando cualquier asomo de reyertas, tratando "este sport como se merece, pues es el último reflejo que de la gran raza guanchinesca queda en nuestras costumbres y el último rayo con que su acrisolada lealtad nos ilumina. Trataremos este espectáculo como obra moralizadora, propia de almas viriles que están muy lejos del ateminamiento ruina de los pueblos y de las naciones" (El Pueblo, 9 de noviembre de 1908: 1).

${ }^{31}$ Como la "gran lucha en la Plaza de Toros de esta Capital [donde], con objeto de que puedan asistir señoras y señoritas, los luchadores saldrán al terrero en traje de punto [...], porque de este modo se conseguirá dar al espectáculo mayor aliciente" (Diario de Tenerife, 22 de mayo de 1908: 1). Todavía en 1922, al "salón de gignacia [sic]" propiedad de la Sociedad 1o de Mayo, en el que ensayan los luchadores adscritos a la sociedad, no se permite la entrada de menores.

${ }^{32}$ Con las descripciones recogidas por las guías de viajes, el Cabildo Insular de Tenerife apoya varias giras de luchadores por Europa, visitando Berna, Zurich o París, entre 1932 y 1935. 
Santa Cruz de Tenerife (Eco del Comercio, 3 de abril de 1861: 2). Hacia 1918 se baraja su fallida inclusión en los programas de educación física militar bajo el auspicio del Reglamento Provisional de Gimnasia para Infantería, de $1911^{33}$. Pero en 1929 pasa a ser incluida en el programa educativo de la Escuela Central de Gimnasia de Toledo (Antequera 1996). Las virtudes y ventajas también son recogidas por Diego Gigou Costa, médico que, en 1907, asevera a las madres canarias que "no hay nada tan pernicioso como la vida sedentaria", cuestión a la que no afecta en nada a los campesinos, que "no necesitan hacer gimnasia artificial, pues ya naturalmente la hacen desde niños [...] sobre todo ejerciéndose en la regional y nobilísima "lucha", en que tanto se desarrolla la fuerza como la agilidad" (Guigou 1907: 262). Y serán retomadas por los proyectos regeneracionistas de adscripción católica en concomitancia con el movimiento de la Acción Social, tomando forma estatutaria en sociedades como La Casa del Obrero (1912), o la Juventud Católica de Santa Cruz de La Palma (1929). Partiendo de la premisa "instruir divirtiendo", y siguiendo las ventajas físico-morales que comporta su práctica, ésta será incorporada de manera ocasional entre los niños acogidos por los "Establecimientos Insulares de Beneficencia" del Cabildo Insular de Tenerife, el Asilo Victoria o las Colonias Escolares de vacaciones. Y el movimiento obrero no quedará al margen, incorporando tanto la práctica, la dotación de espacios de ensayo y práctica, o la constitución de sociedades deportivas de filiación obrera (Alonso Delgado 2014, 2015).

Por último, cabe señalar la impronta del Romanticismo. El movimiento no tiene en Canarias la trascendencia artística y social que tuvo en Europa. La producción artística pasa por contar con una literatura más o menos definida, "pero de una manera débil y dispersa", y con cierta resonancia en el caso de la pintura, la música o la arquitectura (Hernández et al. 2009: 191-192). El intimismo pasa a ser un tema recurrente, "propio del carácter de la región canaria" (op. cit.: 193). En este caso, algunas revistas o semanarios literarios o científicos — como La Aurora (1847), La Revista de Canarias (1878) o Castalia (1917) — incluyen descripciones de la "lucha" donde la consideración del origen indígena y el costumbrismo están presentes ${ }^{34}$. No sólo la producción literaria insular (de alcance culto o divulgativo) seguirá estas coordenadas. Sino que algunos literatos o periodistas relevantes (como Manuel Verdugo, Francisco González Díaz, Luis Álvarez Cruz, Leoncio Rodríguez, Benito Pérez Armas, Diego Crosa, entre otros), serán mentores, organizadores o promotores de eventos o sociedades luchísticas, participando de un "sport tan noble, gallardo y viril" que, cual "tesoro de nuestras herencias guanches [es] una escuela idónea para formar hombres fuertes, ciudadanos idóneos en el doble sentido moral y físico porque no sólo conserva las energías corpóreas, sino que infunde sentimientos de dignidad y nobleza" (González Díaz, en La Verdad, 10 de septiembre de 1917: 1) $)^{35}$.

La confluencia del ideario romántico con el proyecto moderno (del que el deporte forma parte y es partícipe) contribuirá a la confluencia en la "lucha" de la recreación

\footnotetext{
33 En 1918 el Coronel Jefe del tinerfeño Regimiento de Infantería no 64 ve cierto inconveniente en que el nuevo Reglamento de Gimnasia del Cuerpo implante solamente "deportes [que] no sean los del país", ante la orden de desarrollar preferentemente la "afición [a] los que preconizaba el texto [por ser] más útiles" (ARIM. 558, 3423. "Batallón de cazadores Gomera- Hierro" Núm. 23, fols. 8-8v).

${ }^{34}$ Por ejemplo, ver: La Aurora, 19 de septiembre de 1847: 19-22; Diario de La Laguna, 24 de febrero de 1896: 1.

35 Etiquetados como "aficionados", comparten este rol con promotores, industriales o prohombres.
} 
de la figura del indígena (como manifestación de la etnicidad), y los valores atribuidos al deporte moderno. La virilidad, la nobleza, el desprendimiento, el honor... resultan ser ideales atribuidos al sportman moderno, y compartidos con el indígena. El luchador ideal se dispondrá un cuerpo ágil, estético, y eficiente. Donde la fuerza está al servicio de la maña y la intuición. Y donde la hombría permite canalizar las emociones, y redirigirlas, en un sentido positivo, hacia la defensa del honor, la palabra dada o los compromisos adquiridos para con uno mismo, los demás y la "lucha", como fin último.

De este modo, la "lucha" quedará así doblemente legitimada. Representada por un ethos y una representación corporal claramente identificables con el proyecto moderno, y compartidos con el ideario racial atribuida al indígena. En consonancia, los valores recalcados abundarán en estos aspectos, en un intercambio que se produce de manera recurrente y frecuente. Y donde las tensiones o dilemas resultantes pasarán por instaurar idealizaciones del pasado ${ }^{36}$, limitar o restringir los emolumentos percibidos por los luchadores, en un contexto de fuerte mercantilización ${ }^{37}$, entre otras.

\section{LA DIÁSPORA}

Tal y como ha referido Medina en su estudio de la comunidad vasca en Barcelona (2002: 287-292), la existencia de una diáspora condiciona la forma en que se recrea la etnicidad por parte de los emigrantes. Se trata de un proceso en que se articulan o refuerzan diferentes diacríticos. Y que, con el propósito de una "recreación de la identidad y una reivindicación específica y consciente de la etnicidad" (op. cit:: 211), contribuyen tanto a la recreación y a la reivindicación de la identidad grupal, como a mostrarse ante los demás "como somos" (op. cit.: 109) ${ }^{38}$.

A lo largo del periodo tratado, el destino de la diáspora isleña sobre todo se dirige a las Grandes Antillas (especialmente Cuba), Argentina y Uruguay, donde, al igual que ocurre posteriormente en Venezuela, se constituirá un tejido asociativo de cierta importancia. La articulación de los vínculos identitarios pasará por el nexo, más o menos constante, con la comunidad de origen, y el apoyo a causas emprendidas en las islas (en modo de empresas, escuelas, sociedades deportivas, partidos políticos periódicos, etc.). Es un viaje de ida y vuelta que lleva, por ejemplo, a la organización de "luchas"

${ }^{36}$ Con la celebración de festivales musicales y literarios, bailes y festejos, la sociedad organizará luchas en la plaza del pueblo, de entrada pública y gratuitas, como "primer paso que se da para atenuar el grado de mercantilismo a que ha llegado el deporte canario en estos últimos tiempos" (Las Noticias, 6 de septiembre de 1929: 1).

37 En un contexto de creciente mercantilización, el luchador Luis Pagés responde ante la cruzada a favor del amateurismo total, diciendo no creer que "ningún deportista se presente en público para actuar en espectáculos gratuitamente (a excepción de un beneficio (sic)) para que el producto del mismo sea de la empresa pura y exclusivamente [...]. Hoy [...] creo que nadie trabaja por amor al arte... ¡ni antes tampoco!” (La Prensa, 7 de diciembre de 1934: 6).

38 "Pero no en base o con relación con cualquier aspecto aleatorio. Se trata de mostrar quiénes somos en función de "lo nuestro", de nuestro origen, de nuestras raíces. De aquello que, por un lado, nos une — como grupo-, pero que también, por otro lado, nos representa y, en este mismo sentido y al ser nuestro, también nos diferencia de los otros y, por lo tanto, permite una reivindicación concreta y consciente de una identidad propia, diferenciada". 
destinadas a la captación de fondos y recursos para el retorno de emigrantes pobres desde Cuba, en la década de 1930. En la diáspora, el deporte se servirá especialmente de este viaje de ida y vuelta a través del Atlántico. No sólo al captar elementos provenientes de la patria chica, sino también al facilitar el préstamo de términos provenientes de Cuba, como el extendido "luchada" - impuesto al castizo "lucha" (Diario de Tenerife, 27 de mayo de 1908: 2)—, o la penetración de deportes como el baloncesto o el béisbol en las islas de Tenerife y La Palma, en la década de 1930.

La afluencia de luchadores hacia América será frecuente. No sólo se trata de emigrantes que llevan consigo la práctica. También de la organización de espectáculos luchísticos fundamentalmente por y para la diáspora isleña por empresas industriales, promotores —al igual que sucede con la pelota vasca (Medina 2002: 183-190)_, o por la sociedad civil de raíces isleñas ${ }^{39}$. Al menos desde 1848 se celebran combates en teatros de La Habana (Reig 2007), así como en ferias agrícolas o romerías desde 1872, bajo el auspicio de la Asociación Canaria de Beneficencia y Protección Agrícola (1872) (Antequera 1996: 106-113). A partir de la década de 1880 se intensifica la visita y presencia regular de luchadores con cierto renombre en Cuba (VV.AA. 1983; Antequera 1996: 103-149; Ayala 1997: 81-150; Henríquez 1986); y, algo después, también a Argentina o Europa, en un proceso donde la normalización de un espectáculo con fuerte cruce de apuestas (y por tanto, la movilidad interinsular de luchadores), se intensifica. En 1904, desde "Buenos Aires escriben preguntando si podrían ir a aquella Capital, y en qué condiciones, contratados por tres meses, 12 luchadores de estas islas, con objeto de que luchen entre ellos mismos, al estilo del país, en uno de aquellos teatros" (El Noticiero Canario, 3 de agosto de 1904: 2), convocatoria repetida en 1907, esta vez hacia Madrid, nacida, con toda probabilidad, del bisoño Centro de Propaganda y Turismo de Tenerife (Diario de Tenerife, 21 de octubre de 1907: 2). "La juventud republicana canaria que reside en Buenos Aires, atenta al recuerdo de la tierra", organiza luchas en varios teatros con motivo de las fiestas del Centenario de la República Argentina (ibid., 10 de abril de 1910: 1), algo que se repite, al menos, tres años después mostrando para que "en la arena, en el "terreño", nuestros atletas hagan honor a la lucha canaria" (La Prensa, 8 de octubre de 1913: 1-2). La Asociación Canaria de La Habana (1906) organizará un "Field Day canario" en terrenos de su propiedad, a las afueras de La Habana, "figurando, entre otros números, la típica lucha" (La Prensa, 19 de junio de 1924: 1). A raíz del crack de 1929, la visita de luchadores cesará casi por completo. No así la presencia en la diáspora en las distintas sociedades (deportivas, culturales, benéficas...) o centros regionales constituidos en zonas de acogida migratoria canaria a partir de la década de 1940, como Venezuela o el Sahara (Antequera 1996: 381-426; Hernández et al. 2000: 31-32), en un periodo que escapa a este trabajo.

\footnotetext{
39 Como la Asociación Canaria de Beneficencia y Protección Agrícola (1872), la Asociación Canaria de la Habana (1906), o la Sociedad de Beneficencia Canaria (1917) en Cuba; la Juventud Republicana Canaria o el Club Cultural y Deportivo Canario, existentes en Buenos Aires en la década de 1910; o la Asociación Canaria de Montevideo, en 1927.
} 


\section{BIBLIOGRAFÍA CITADA}

Alonso, Víctor. En prensa. "La lucha canaria en Tenerife en el contexto de la Gran Guerra (19141918): las primeras sociedades luchísticas". XXI Coloquio de Historia Canario- Americana (2014).

Alonso, Víctor. 2015. Deporte, Educación, Ocio y Disciplinamiento: La sociabilidad en las Islas Canarias Occidentales (1850-1936). Santa Cruz de Tenerife: Idea.

Antequera, Francisco. 1996. La Lucha Canaria. Algo más que un deporte. Santa Cruz de Tenerife: CCPC.

Ayala, Antonio. 1977. La lucha canaria. Las Palmas de Gran Canaria: Excma. Mancomunidad de Cabildos de Las Palmas.

Barbero, José Ignacio. 1991. "Sociología del deporte. La configuración de un campo". Revista de Educación 295: 345- 378.

Barreto, Carmen Marina. 1996. "Construyendo identidades: juegos y deportes tradicionales canarios", en Fernando Amador Ramírez et al. (eds.), I Congreso Internacional de luchas y juegos tradicionales: 23-36. Madrid: Gobierno de Canarias.

Bartra, Roger. 1996. El salvaje en el espejo. Barcelona: Destino.

Baucells, Sergio. 2009-10. "Las fuentes narrativas canarias y la construcción ideológica del indígena". Tabona. Revista de Arqueología y Prebistoria 18: 9-34.

Baucells, Sergio. 2012. Los aborígenes canarios y la reconstrucción de la identidad. De la antítesis a la sintesis. Santa Cruz de Tenerife: FCCEC.

Bethencourt, Juan. 1994. Historia del Pueblo Guanche (Tomo II). Etnografía y organización sociopolítica. La Laguna: Francisco Lemus Ed.

Bourdieu, Pierre. 1996. "Programa para una sociología del deporte", en Cosas dichas: 173-184. Barcelona: Gedisa.

Bourdieu, Pierre. 1997. Razones prácticas. Sobre la teoría de la acción. Barcelona: Anagrama.

Bourdieu, Pierre. 2000. “¿Cómo se puede ser deportivo?", en Cuestiones de Sociología: 173-194. Madrid: Istmo.

Bourdieu, Pierre. 2002. Las reglas del arte. Génesis y estructura del campo literario. Barcelona: Anagrama.

De Olivera, Juan. 1969. Mi álbum (1858-1862). La Laguna: IEC.

De Viera, José. 1991. Historia de Canarias (2 vols.). Las Palmas de Gran Canaria: Gobierno de Canarias.

Dunning, Eric. 2003. El fenómeno deportivo. Estudios sociológicos en torno al deporte, la violencia y la civilización. Barcelona: Paidotribo.

Elias, Norbet y Eric Dunning. 1992. Deporte y ocio en el proceso de civilización. México: FCE.

Eriksen, Thomas. 1993. Ethnicity and Nationalism. Anthropological Perspectives. Londres: Pluto Press.

De Espinosa, Alonso. 1980. Historia de Nuestra Señora de Candelaria. Santa Cruz de Tenerife: Goya Ed.

Estévez, Fernando. 1987. Indigenismo, raza y evolución. El pensamiento antropológico canario (17501900). Santa Cruz de Tenerife: ACT.

García, Manuel, Nuria Puig y Francisco Lagardera (eds.). 1998. Sociología del deporte. Madrid: Alianza.

García, Francisco y Guillermina Casanova. 2014. Origen e bistoria de la lucha canaria. Santa Cruz de Tenerife: Idea.

Ghirlanda, Virgilio. 1925. La Lucha Canaria. Santa Cruz de Tenerife: La Prensa.

González, Francisco. 1910. Cultura y Turismo. Las Palmas de Gran Canaria: Tipografía del Diario Buenos Aires.

Guigou, Diego 1907. Los niños canarios. Ensayo de higiene regional infantil consagrado especialmente a las madres de familia. Santa Cruz de Tenerife: Imp. y Lit. de Ángel Romero.

Grignon, Claude y Jean-Claude Passeron. 1992. Lo culto y lo popular. Miserabilismo y populismo en sociología y en literatura. Madrid: La Piqueta.

Henríquez, Santiago. 1986. Historia de la Lucha Canaria. Telde 1870-1985. Las Palmas de Gran Canaria.

Hernández, José, José Martín y Andrés Mateos. 2000. Lucha Canaria. Historia, Estructura y Técnica. Santa Cruz de Tenerife: Gobierno de Canarias.

Hernández, María, Gerardo Fuentes y Carlos Gaviño. 2009. El despertar de la cultura en la época contemporánea. Artistas y manifestaciones culturales del siglo XIX en Canarias. Santa CruZ de Tenerife: Gobierno de Canarias. 
Holt, Richard. 1989. Sport and the British. A modern history. Oxford: OUP.

Hutchinson, John y Anthony Smith (eds.) 1996. Ethnicity. Oxford: OUP.

Marx, Karl. 1976. Contribución a la crítica de la economía política. Madrid: Alberto Corazón.

Medina, Xavier. 2002. Vascos en Barcelona. Etnicidad y migración vasca hacia Cataluña en el siglo XX. Vitoria-Gasteiz: Eusko Jaurlaritzaren Argitalpen Zerbitzu Nagusia.

Medina, Xavier y Ricardo Sánchez (eds.) 2003. Culturas en juego. Ensayos de antropología del deporte en España. Barcelona: Icaria- Institut Catalá de Antropología.

Medina, Xavier y Ricardo Sánchez. 2006. "Introducción. La antropología del deporte en España: Visión crítica y perspectivas de futuro". Revista de Dialectología y Tradiciones Populares LXI (2): 7- 17.

Moscoso, David. 2006. "La sociología del deporte en España. Estado de la cuestión". Revista Internacional de Sociología 64 (44):177- 204.

Pujadas, Xavier (comp.) 2011. Atletas y ciudadanos. Historia social del deporte en España. 1870 2010. Madrid: Alianza.

Rivero, Emilio. 2007. Crónicas de la lucha canaria. Historias del tiempo viejo. La Laguna: Gobierno de Canarias-CCPC.

Sánchez, Salvador. 1987. Temas de Lucha Canaria. Santa Cruz de Tenerife: CCPC.

Saramago, José. 2008. El viaje del elefante. Madrid: Alfaguara.

Sztopmka, Piotr. 1993. Sociología del cambio social. Madrid: Alianza.

Thomas, Raymond, Antoine Haumont y Jean Levet. 1988. Sociología del Deporte. Barcelona: Bellaterra.

Viera, Isaac. 1916. Costumbres canarias. Madrid: Renacimiento.

Vigarello, Georges y Richard Holt. 2005. "El cuerpo cultivado. Gimnastas y deportistas en el siglo XIX", en Alain Corbin (ed.), Historia del cuerpo (vol. II): de la Revolución Francesa a la Gran Guerra: 295-354. Madrid: Taurus.

VV.AA.1983. La Lucha Canaria y D. Tomás Zamora y otros artículos. Santa Cruz de Tenerife: Caja General de Ahorros de Santa Cruz de Tenerife.

Wahl, Alfred. 1996. "La querella de los orígenes". El Viejo Topo 94: 27-31.

Wahl, Alfred. 2002. La balle au pied. Histoire du football. Paris: Gallimard.

Fecha de recepción: 7 de julio de 2015

Fecha de aprobación: 16 de diciembre de 2015 